\title{
Plantas mesoamericanas subutilizadas en la alimentación humana. El caso de Guatemala: una revisión del pasado hacia una solución actual (ISBN: 978-9929-620-12-4)
}

José V. Martínez Arévalo*

Facultad de Agronomía, Universidad de San Carlos de Guatemala, Guatemala

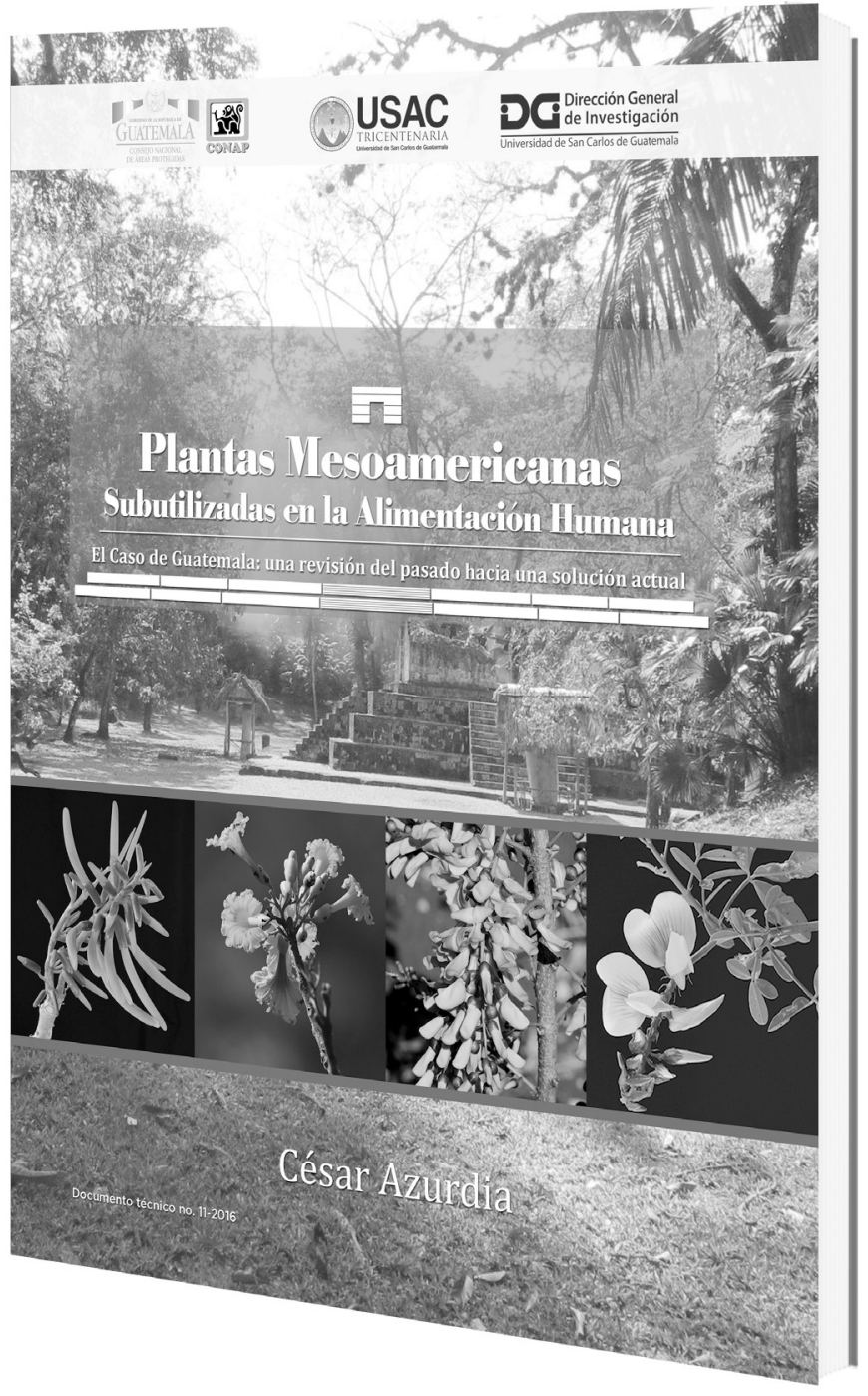

Recientemente se ha publicado el libro Plantas mesoamericanas subutilizadas en la alimentación humana. El caso de Guatemala: una revisión del pasado hacia una solución actual. Esta es una interesante obra por el tema que trata, pero más interesante cuando se lee el capítulo II, que se refiere a la relación entre la 
biodiversidad y la seguridad alimentaria. Esta sección proporciona un elemento diferencial con otras obras similares, ya que pone en relieve la relación cultural con las especies locales poco conocidas. A este respecto es importante considerar que Guatemala como país megadiverso, tiene en la parte de la agro biodiversidad muchas especies útiles en la alimentación, algunas de ellas como el maíz y el frijol de amplio uso. Sin embargo, hay otro gran número que tiene un uso restringido, unas menos conocidas y utilizadas que otras.

En este libro identifico varias de esas especies que es importante incluirlas en la dieta del área rural. La propuesta del autor, César Azurdía, de utilizar las especies en tres niveles: consumo local, para su comercialización y en la investigación científica para permitir su proceso de domesticación, es importante tomarla en consideración en los programas de seguridad alimentaria estatal de los países mesoamericanos. Los graves problemas en alimentación y nutrición que se vienen dando con más frecuencia y en más regiones de Guatemala, debería ser una preocupación constante de las instituciones del Estado, para promover políticas públicas encaminadas hacia una verdadera soberanía alimentaria, basada en los recursos naturales que tiene el país. Para esto es imprescindible el conocimiento de la biodiversidad útil y su valoración. El libro está elaborado con información de experiencias del autor y una revisión exhaustiva de bibliografía especializada. Se hace el tratamiento de especies nativas de Guatemala poco conocidas y con alto potencial alimenticio $\mathrm{y}$ algunas otras especies introducidas.

La obra contiene información de 41 especies, identificadas por su nombre común y nombre científico.
Se describen agrupadas en aquellas plantas o vegetales utilizadas por sus hojas, por ejemplo Malvilla (Anoda cristata), Mozote (Bidens pilosa) y Tunay (Dahlia imperialis); flores e inflorescencias, por ejemplo chufle (Calathea allouia), Muta (Bromelia pinguin) y Tepejilote (Caludovica utilis); frutos, por ejemplo Árbol de Campeche (Prosopis juliflora), Cericote (Cordia dodecandra) y Manzanita (Vaccinium confertum); semillas, por ejemplo Chan (Salvia hipanica) y Morro (Crescentia alata) y rizomas, por ejemplo Yuquilla (Maranta arundinacea). Cada ficha contiene la descripción de la especie auxiliada con fotografías de alta calidad, distribución, origen y uso en la alimentación.

Cabe resaltar de cada ficha el mapa de distribución en Mesoamérica, que es una parte novedosa en este documento, por la metodología utilizada para su generación. También es importante la información del contenido nutricional actualizado de la mayoría de especies. Por último sus usos en alimentación, que en varios casos llega al nivel de recetas, lo que permite valorar mejor su uso.

El autor tiene una amplia experiencia en el tema de los recursos fitogenéticos, que inicia desde la década de 1980. En otras oportunidades ha aportado para el conocimiento y utilización de otras especies nativas. Esto garantiza la calidad de la información presentada. Es una obra producto del esfuerzo editorial conjunto de la Dirección General de Investigación (Digi) de la Universidad de San Carlos de Guatemala y el Consejo Nacional de Áreas Protegidas (Conap), que contribuyen al conocimiento de nuestra rica biodiversidad mesoamericana. 